\title{
EL USO DIDÁCTICO DE LA FÁBULA EN LA LITERATURA RENACENTISTA ALEMANA
}

JUAN LUIS MONREAL PÉREZ

Facultad de Educación. Universidad de Murcia ${ }^{1}$

\begin{abstract}
Resumen
El presente artículo examina, en el contexto del Humanismo renacentista europeo, el uso de la fábula en la Alemania renacentista y, más concretamente, la utilización de la misma por parte de humanistas renacentistas alemanes como Lutero y Melanchton. Estos reformadores alemanes vieron la utilidad didáctica de la fábula como medio para acceder al conocimiento general de la lengua y para adquirir sentido crítico en la vida. Igualmente consideraron que la fábula, en cuanto género literario, era un instrumento eficaz para el aprendizaje escolar. El interés de acercar los textos a los lectores les llevó a cultivar el género de los proverbios, los adagios, los refranes y la fábula con la finalidad de hacer el lenguaje accesible, cuestión que les era fundamental en su concepción de la lengua.
\end{abstract}

Palabras clave: Fábula, Proverbio, Refrán, Realidad, Ficción.

\begin{abstract}
This article analyzes the use of the fable in European Renaissance, specifically in German Renaissance Humanism, and it's used by Luther and Melanchton as members of this movement. They realized how useful they were didactically to enhance the access to general linguistic knowledge and a critical approach to the issues of their life. Moreover, they considered the literary form of the fable an effective instrument for the learning period. The will to approach texts to the reader made them deal with the literary form of proverbs, adagia, refrains and fables to bring language closer and more familiar, what was benchmark in their concept of language.
\end{abstract}

Key words: Fable, Proverb, Saying, Reality, Fiction.

\section{EL RENACIMIENTO ALEMÁN: REFORMA Y EDUCACIÓN}

El renacimiento alemán, en líneas generales, participa de la filosofía humanista que caracteriza a todo el renacimiento europeo. Ésta no es simplemente la vuelta a lo antiguo, al estudio de las letras y artes de Roma y Grecia, sino la actitud con que se realiza: el hombre es la base del pensamiento del Humanismo renacentista (Paris, 1962: 246, 252-253).

El Humanismo es, pues, un medio y un camino para conseguir el renacimiento de la

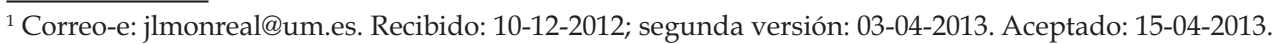


propia civilización. No es mera imitación de lo antiguo sino reelaboración a partir de su propia situación histórica y cultural (Mourelle de Lema, 1993: 85).

Considerando lo señalado anteriormente, se puede indicar que los términos Renacimiento y Humanismo están marcados por un carácter histórico y por una filosofía de renovación del hombre que busca su armonía con el universo natural (Ortega, 2002: 18).

En Alemania, tal como sucedió en los países europeos más impregnados del Humanismo renacentista, en los tres primeros decenios del siglo XVI se produjo un clima muy favorable hacia todo lo que suponía renovación, nuevos valores y recuperación de la cultura antigua a través del acceso a los estudios profanos, principalmente, los clásicos (Monreal, 2012: 191). Los humanistas en Alemania, al igual que sucedió también en otros países europeos (Vidal, 2008: 32-37), formaron un colectivo creciente, ávido de cambios y muy sensible a verse atraído hacia aquellos personajes que se pusieron a la cabeza de lo que representaban los valores más significativos del Humanismo renacentista, como es el caso de Lutero y Erasmo (Lilje, 1986: 39).

Los humanistas alemanes vieron en Lutero, más que un líder de la religión y la teología. Lo que identificaron en él fue un gran defensor de aquellos valores humanistas, considerados como elementos de regeneración de la vieja sociedad, tales como la estima por los estudios profanos clásicos, el rechazo de la literatura basada en la teología especulativa y la necesidad de una nueva enseñanza que conllevara un cambio fundamental en la organización escolar (Grane, 1975: 108-110).

En la reforma de la enseñanza y en la nueva organización escolar que emprende la reforma protestante, Lutero se auxilia para tal misión de su amigo y estrecho colaborador como fue Melanchton, puesto que ambos coincidían en la necesaria reforma que había que llevar a cabo, independientemente de que en algunas cuestiones fundamentales disintieran. Ambos jugaron en la cuestión de la enseñanza un papel importante y cada uno con una función distinta: Lutero, por su parte, como inspirador de la reforma y, Melanchton, como el ejecutor. Lutero, en este campo de la educación, por puro pragmatismo, muestra su cara de humanista (Egido, 2006: 27).

Sin embargo, las expectativas que los humanistas alemanes depositaron en Lutero como hombre humanista, pronto se fueron desvaneciendo, a medida que el monje alemán se fue radicalizando en la cuestión religiosa y teológica y se produjera en Alemania la revolución religiosa. Ello supuso el desplazamiento del interés por el proyecto de la reforma humanista y la entrada del conflicto religioso que consumó la Reforma Protestante. Esta situación hizo que el florecimiento humanista alemán se viera truncado y no lograra consolidar algunas de las reformas que anunciaba, sobre todo en lo relativo a la enseñanza (Jansen, 1925: Parte Segunda, 179). 


\section{USO DE RECURSOS LITERARIOS EN EL RENACIMIENTO EUROPEO.}

Para los humanistas renacentistas europeos era muy importante hacer accesible el conocimiento antiguo y real al pueblo a través del uso del lenguaje, independientemente de la lengua utilizada, fuera el latín o una lengua vernácula. La accesibilidad al conocimiento no era incompatible con el rigor del mismo; a tal fin, se usaban la fábula, el proverbio, el refrán, y se recurría en los libros denominados misceláneas y florilegios al uso de citas, modismos, sentencias, anécdotas, exempla y otras flores de erudición clásica que servían a la par de alimento para el espíritu y de pábulo para la composición literaria, y ello con el objetivo de poner al alcance del lector el saber del mundo antiguo (Serrano, 1992: 49).

Aparte de la fábula ${ }^{2}$ como recurso literario que utilizaron los humanistas renacentistas europeos, entre los que están Lutero y Melanchton, también se usaron otros recursos literarios, como el proverbio y el refrán, tal como hicieron Erasmo, Juan de Valdés y Sebastián Franck. Entre estos tres recursos literarios hay estrecha relación y todos ellos forman parte del contenido de los libros llamados misceláneas y florilegios. Atendiendo a dichos usos, se examinan, previamente, las aportaciones de Erasmo, Valdés y Franck, relevantes humanistas europeos, al proverbio (adagia) y al refrán, antes de centrarnos en la fábula con Lutero y Melanchton.

El primero, Erasmo, incorporó proverbios en su obra Adagia (1500), y en la que la fábula es una parte de la misma; y el segundo, Valdés, usó los refranes en su obra Diálogo de la lengua (1535). En ambas situaciones, sus aportaciones literarias tienen carácter didáctico y se trata, en el caso de Erasmo, de una colección de proverbios que reflejan la sabiduría del mundo clásico antiguo; y, en el caso de Juan de Valdés, con sus refranes antiguos castellanos, busca poner en valor la lengua real.

Erasmo transita por el mundo clásico no de forma superficial y resultado de este camino es la obra Adagia, orientada a exaltar la cultura humanista de las letras y escrita para fomentar el pensamiento y la lengua latina.

Un rasgo de Erasmo a resaltar, en su condición de filólogo, es el esfuerzo que hizo en toda su obra y, particularmente en sus Adagia, para hacerla accesible y comprensible a todos. La orientación didáctica de esta obra constituyó un objetivo importante, siguiendo en éste como en otros aspectos la línea del humanismo. Esto explica que alcanzara en Europa un considerable éxito y fuera una de las obras más leídas por parte de los estudiosos de la latinidad.

Erasmo al referirse a la fábula en los Adagia, utiliza los términos latinos fabula, fabella y apologus, asignándole al primero de ellos, fabula, los mismos referentes que poseía en la literatura latina. Además, la inclusión que Erasmo hace de la fábula en la

\footnotetext{
${ }^{2}$ No es objetivo de este artículo analizar este género literario, sino el uso que del mismo se ha hecho en un periodo histórico-cultural determinado como es en el Renacimiento alemán. En cualquier caso, sí queremos señalar que con la denominación fabula, a lo largo de la historia de este género literario se han abordado otras composiciones y sentidos literarios próximos (Talavera, 2007: 30-31); ello explica que la fábula sea "un género popular y tradicional, esencialmente 'abierto', que vive en infinitas variantes" (Rodríguez Adrados, 1979: 11).
} 
colección de proverbios que contiene la obra Adagia, se explica por la relación que desde antiguo se establecía entre fábula y proverbio y que la tradición humanista reforzó aún más. Tan estrecha es la vinculación entre estos dos términos que la fábula puede expresarse en un proverbio en forma de moraleja; y, a su vez, éste puede generar una fábula (Serrano, 1992: 50-54).

El segundo, Juan de Valdés, recoge también la tradición renacentista que relaciona proverbios y refranes y, a su vez éstos con las fábulas esópicas. Con este legado de géneros literarios, Valdés propone en su obra Diálogo de la lengua el uso de los refranes antiguos, como verdadero patrimonio de la lengua real, ante la falta de buenas obras y autores que marquen la dirección de la perfección en la lengua castellana. Los refranes, en su opinión, aunque nacidos del vulgo, sin embargo son testimonio del uso auténtico y generalizado de ciertas formas léxicas y sintácticas (Barbolani, 2006: 71).

El recurso a los refranes que presenta Valdés como medio de mejorar la lengua, no cabe duda que es una clara alternativa a la búsqueda de la perfección de la lengua por la vía del latinismo y cultismo. (Valdés, 1997: 246-247).

Con la utilización del recurso de los refranes, Valdés es consciente de que entronca con toda una tradición literaria de orientación concreta y real, que tanto en el pasado, época medieval, como en el presente, había tenido su éxito y eficacia en el desarrollo de la lengua española en términos concretos y, en términos generales, había enriquecido la lengua como instrumento de comunicación, tal como Erasmo hizo en sus Adagia (Lapesa, 1974: 15).

En suma, lo que se manifiesta en Valdés a través de su amor y aprecio de los refranes es la atracción que siente por la lengua popular. En ella ve la sobriedad del estilo y la nitidez en la expresión, que no son más que rasgos naturales de la perfección de la lengua (Valdés, 2011: 162).

Por último, Sebastián Franck, humanista alemán (1499-1542), vivió como los de su generación, entre el ambiente que dominaba a finales de la Edad Media, el escolasticismo, y la influencia del humanismo que sentaba las bases de la nueva cultura. Su aportación, desde el territorio alemán, al recurso literario de los proverbios ha sido significativa, con la publicación de una colección de proverbios (Sprichwörter) en 1541 en Frankfurt (Franck:1541); ésta fue reimpresa varias veces con variaciones y logró tener amplia aceptación, precisamente por el carácter popular que Franck le dio a esta obra (Cáceres y Martín-Gaitero, 1994:101).

En la contribución de Franck al género de los proverbios, se recoge la tradición medieval alemana en este campo, pero también es manifiesta la influencia de otros humanistas europeos en esta obra, como la de Vives y sobre todo la de Erasmo:

[...] ya que no cree necesario citar el nombre de Erasmo, pues, [...] no hay refrán traducido del latín que no haya sido tomado de los 4.150 Adagia señalados y comentados anteriormente por Erasmo (Gilly, 2005:272).

Conviene señalar, finalmente, que la aportación literaria de Franck a través de su colección de proverbios, aún siendo importante, ha quedado relegada a un segundo 
plano, por haber ocupado un primer plano su controvertida posición teológica, su radical crítica a la Iglesia institucional, incluida a la reformada (Koyré, 1981:36), y sus otras obras como Chronica y Paradoxa, de carácter teológico-religioso, que produjeron fuertes reacciones entre los responsables de las iglesias y entre los líderes del pensamiento teológico-religioso del momento.

\section{USO DE LA FÁBULA COMO RECURSO LITERARIO EN EL RENACIMIEN- TO ALEMÁN}

La fábula es otro relevante recurso literario utilizado en los llamados libros misceláneas y florilegios y muy utilizado por la literatura renacentista alemana. El término del alemán antiguo (Mittelhochdeutsch) 'fabele', proviene del latín 'fabula' y fue calificado por Phaedrus como un género literario (Fabulae Aesopicae). Las Fábulas de Esopo fueron traducidas al alemán por el humanista alemán Heinrich Steinhöwel (1412-1482), y cuya fama ha estado siempre relacionada con la traducción de dicha obra. La primera traducción de las Fábulas de Esopo la hizo en latín-alemán, en la versión titulada "Ulmer Aesop" y publicada por primera vez en 1476 en Ulm. En los años siguientes, Steinhöwel continuó traduciendo las Fábulas de Esopo, así como otras obras significativas, como algunas de Petrarca y Boccaccio, lo que hizo que sus trabajos fueran conocidos en Europa; ello contribuyó a su reconocimiento como relevante humanista alemán, muy inspirado por el Renacimiento italiano y dotado de una sólida y diversa formación ${ }^{3}$.

El proceso de incorporación de la fábula a la literatura alemana toma cuerpo en la Edad Media en el ámbito germánico; en esta época ya existía una rica tradición en este género (Dicke y Grubmüller:1987) y se le asignaba también una función (Grubmüller:1977). Desde estos antecedentes y bajo esta influencia se explica la posterior contribución de Steinhöwel a la Fábula. Ya en este tiempo este género literario se expresaba por los términos bîspel o bîshaf, que en alemán moderno equivalen al término ejemplo. Ambos términos muestran, que se trata de una narración educativa. La palabra bîspel indica la relación entre fábula, parábola y refrán. Se refiere a una narración que no se representa a sí misma, sino que representa otra cosa, cuyo sentido no reside en lo que se cuenta. Al respecto Reinhard Dithmar señala que "concretamente, en el siglo XIII se despreció el término spel pasando a ser lo que no tiene ningún significado implícito o incluso una narración descabellada, mientras que bîspel muestra lo verdadero, bajo el envoltorio de lo que entretiene. También las parábolas y alegorías bíblicas se denominan bîspel [...]. En la Literarura Medieval se denominan las fábulas de Esopo como bîspel (Dithmar, 1988: 163) .

\footnotetext{
${ }^{3}$ Tiene interés al respecto el artículo de G. Dicke sobre el Esopo de H. Steinhöwels. Lo califica de interés universal y de muy comprensible para la prosa alemana (Dicke:1994).

${ }^{4}$ La traducción de la cita ha sido realizada por el autor del artículo, cuyo texto en el original alemán es el siguiente: Bereits im 13. Jahrhundert wird der Begriff spel (Erzählung, Bericht) abgewertet zur nicht verbürgten und somit unwahren oder sogar lügenhaften Erzählung, während bîspel als die -von einer unterhaltsamen Hülle umgeben- Wahrheit erscheint. Auch das biblische Gleichnis wird bîspel genannt [...]. In der mittelalterlichen Spruchdichtung werden die äsopischen Fabeln als bîspel bezeichnet.
} 
La larga tradición de la fábula en Alemania y el interés por su valor educativo en épocas donde había una gran preocupación social por la tradición cultural hace que analicemos este género literario a través del uso que hizo del mismo Lutero.

\section{EL USO DE LA FÁBULA COMO GÉNERO LITERARIO POR LUTERO Y MELANCHTON}

Lutero entendió perfectamente que el éxito de su mensaje, oral y escrito, residía en hacer de la lengua y del lenguaje un verdadero instrumento de comunicación con sus oyentes y lectores, a través de las formas literarias convenientes para convertirlo en atractivo.

Un ejemplo de la calidad del lenguaje empleado por Lutero se ve reflejado en sus Charlas de Sobremesa o las Tischreden, en alemán, y cuya edición fue tardía. Éstas recogen una temática muy variada sobre distintas cuestiones de la vida de Lutero y que fueron recordadas por éste ante los comensales que formaban un círculo familiar reducido.

El valor de estos textos, las Tischreden, es considerable y reflejan bien el uso del lenguaje por parte de Lutero. El hecho de que éstos no fueran escritos directamente por él no le restan valor, ya que los copistas de los textos -como señala Egido-,

[...] los transcribieron con mimo. Por eso, en las ediciones críticas, se pueden contrastar las lagunas y defectos de sus notas apresuradas. Pero también gracias a su cuidado se puede gozar de estos dichos, expresados en estilo tan de Lutero, es decir, con trazos que a veces rayan en lirismo y en otras -muchas- ocasiones se recrean en resortes del peor gusto, con la inevitable apoyatura en las referencias sexuales (Egido, 2006: 426).

Este interés de acercar los textos a los lectores le llevó a Lutero a cultivar el género de los proverbios, los adagios, los refranes y la fábula con la finalidad de hacer el lenguaje accesible, cuestión que le era fundamental en su concepción de la lengua.

La fábula, entre estos recursos literarios, era para Lutero muy apreciado, sobre todo porque le veía una gran utilidad didáctica, como más adelante se indicará. Su interés por este género literario le llevó a conocerlo bien y a familiarizarse con el mismo. Por ello, sintió una gran admiración por Esopo, valorando sus escritos considerablemente, traduciendo sus fábulas que, por otra parte, le sirvieron de referente en sus obras.

Prueba de la valoración que hacen, tanto Lutero como Melanchthon, de la utilidad de la fabula, como recurso didáctico, es su propuesta de utilizar las fábulas de Esopo en la nueva orientación de la enseñanza que propone la reforma protestante. Al respecto, es ilustrativo el siguiente fragmento:

Así, según lo establecen las Instrucciones para los Visitadores de las Escuelas Parroquiales ('Unterricht der Visitatoren an die Pfarherrn im Churfürstenthumb zu Sachsen') -documento escrito conjuntamente por Lutero y Melanchthon en 1528 con el fin de normar el funcionamiento de estas escuelas-, la educación básica debía constar de tres etapas. En la primera de ellas los niños aprenderían a leer y escribir en latín, enriquecerían su vocabulario y se les dictaría los primeros rudimentos de gramática. La segunda etapa estaría dedicada por completo a la gramática y a las primeras lecturas de obras de autores clásicos (como, por ejemplo, las fábulas de Esopo). 
Finalmente, en la tercera etapa se les daría a los estudiantes obras de autores como Virgilio, Ovidio, Cicerón y se les introduciría al estudio de la lógica y de la retórica. (Suárez, 2003: 22).

Fruto del interés de Lutero por la fábula como género literario, es su traducción de las fábulas de Esopo; para dicho trabajo se apoyó en textos alemanes preexistentes, además de tener en cuenta también otras obras escritas en latín.

En cuanto al uso que Lutero hizo de la fábula, éste siguió la tradición renacentista al respecto, utilizándolas para facilitar la lectura y divulgar las moralejas contenidas en las mismas. Aparte de esta función didáctica general, Lutero utiliza este recurso literario para criticar las conductas de los papistas, de determinados personajes políticos y religiosos, de determinados sectores de la sociedad de su tiempo, mediante expresiones relacionadas con animales sacados de las fábulas de Esopo. Con este uso, Lutero reproduce la práctica habitual de este género literario que ejemplifica modelos morales, tanto para resaltar las virtudes del ser humano como para criticar las miserias de las conductas, por ser desacertadas y censurables (Abraham et al., 2009: 124).

No faltan fragmentos en las obras de Lutero en los que hace crítica de diferentes situaciones $\mathrm{y}$, a tal fin, utiliza moralejas derivadas y relacionadas con el género de las fábulas. A modo de ejemplo, presentamos algunos fragmentos de obras de Lutero, que testimonian el objetivo y la finalidad de este recurso literario: ${ }^{5}$

1. Obra: 'La libertad del cristiano' (Von der Freiheit eines Christenmenschen, 1920).

Más que obra, podría decirse obrilla o tratadillo. Pertenece a los escritos de reforma y se caracteriza por cierta orientación mística.

Lutero plantea en este fragmento el problema de la justificación, tema central de su teología, en los siguientes términos y, precisamente es en ese contexto en el que recurre a las fábulas 1 y 4 de Fedro:

Honor tal lo consigue el cristiano por la fe solo, no por obras. Bien claro se ve por lo dicho cómo el cristiano está libre de todo, está sobre todas las cosas; por lo mismo no tiene precisión de recurrir al concurso de ninguna buena obra para su justificación y salvación: la fe se lo otorga todo sobreabundantemente. Si fuese tan necio como para pensar que puede conseguir la santidad, la libertad por una obra buena, perdería la fe y todo lo demás: le pasaría exactamente igual que al perro que llevaba una tajada de carne en las fauces: quiso atrapar la carne que se reflejaba en el agua y se quedó sin la carne y sin su reflejo (Lutero, 2006: 163).

2. Obra: 'A los magistrados de todas las ciudades alemanas, para que construyan y mantengan escuelas cristianas' (An die Radsherrn aller Stedte deutsches Lands: Das sie Christliche Schulen auffrichten und hallten sollen, 1523). También en este caso es una pequeña obra. Se trata de un alegato en favor de la educación, que constituyó un pilar fundamental de su reforma.

En el siguiente fragmento, Lutero al hacer una fuerte crítica en relación a la mala enseñanza del latín por culpa de profesores ignorantes, incorpora la correspondiente moraleja, como parte de la fábula:

\footnotetext{
${ }^{5}$ Está marcado con cursiva, la parte del texto que corresponde a dicho genero literario.
} 


\begin{abstract}
¿No ha sido una lamentable calamidad lo sucedido hasta ahora, cuando un muchacho tenía que emplear veinte años o más para aprender un latín tan deleznable, sólo para hacerse cura o leer la misa $[. .$.$] ¿Quién es el culpable de lo ocurrido? No había más libros que los necios$ frailes y «sofistas». ¿Qué otra cosa podía salir que discípulos y maestros zafios, como zafios eran los libros en los que tenían que estudiar? Un grajo no puede criar palomas ni un loco personas inteligentes (Lutero, 2006: 163).
\end{abstract}

\title{
3. Obra: 'Del arte de traducir' (Sendbrief vom Dolmetschen, 1530).
}

Esta obra es realizada bajo la forma literaria de epístola y enviada a su amigo Wenceslao Link; en ella transmite su pensamiento acerca de la traducción y de la exégesis. El origen de la obra reside en la polémica que Lutero mantuvo con los papistas a propósito de haber añadido 'sólo por la fe', a su traducción del texto de la Biblia Arbitramur hominen justificari ex fide absque operibus, ya que así, dice Lutero, la lengua resulta más ingeniosa y armoniosa con la lengua alemana. Resultado de la fuerte agresividad de Lutero ante esta situación, es el uso frecuente en esta obra de moralejas, nuevamente vinculadas a fábulas. Veamos dos ejemplos:

Si alguna falta he cometido (de lo que no tengo conciencia, puesto que a sabiendas ni una letra he traducido de forma inexacta) a lo que no estoy dispuesto es a tolerar que los papistas se constituyan en jueces sobre ello: sus «ija-ija» son demasiado flojos para juzgar mis traducciones. Sé muy bien el arte, la entrega, el sentido común y la inteligencia que requiere el buen traducir: de esto saben menos ellos que el asno del molinero, puesto que nunca han puesto mano a la obra (Lutero, 2006: 308).

Estoy decidido a seguir despreciándolos mientras sigan siendo gente (quiero decir borricos) de esta calaña. Porque entre ellos hay insolentes tan descarados como el doctor Schmidt, el doctor Rotzlöffel y similares, que jamás han aprendido su propia ciencia, es decir, la ciencia de los sofistas, y sin embargo, se lanzan contra mí en estas cosas que no sólo superan toda sofistería, sino que también (como dice San Pablo) se encuentran muy por encima de toda la sabiduría del mundo y de la razón. No tiene que esforzarse el asno por cantar, porque por las orejas se le distingue inmediatamente (Lutero, 2006: 310).

En la historia de la formación de la fábula están presentes, tanto elementos reales como simbólicos o ficcionales de la sociedad. A la parte ficcional "se le supone el camuflage o extravío del sentido que encierra" (Certeau, 2006: 21). La presencia de estos dos elementos, por una parte, puede crear confusión a veces y, por otra, puede requerir en determinadas expresiones, interpretación de lo que realmente quiere significar.

Esta doble significación -género literario y expresión de la ficción literaria o discurso irreal- "ha conducido, en opinión de Dithmar, hasta nuestro siglo a malentendidos, a causa de los cuales las fábulas de Esopo sufrieron injustamente el descrédito"6 (Dithmar, 1988: 164).

Lutero superó la confusión entre el concepto del género de la fábula y el de la creación ficcional, al aunar crítica de la realidad y valor didáctico de ese género

\footnotetext{
${ }^{6}$ La traducción de la cita ha sido realizada por el autor del artículo, cuyo texto en el original alemán es el siguiente "Diese Doppelbedeutung -Gattungsbezeichnung und Ausdruck für erdichtete, unwahre Rede- hat bis unser Jahrhundert immer wieder zu Mißverständnissen geführt, durch welche die äsopische Fabel zu unrecht in Mi $\beta$ kredit geriet".
} 
literario. Sin embargo, es una confusión injustificada ya que en ambos casos se critica la realidad. Al respecto, de nuevo señala Rheinhard Dithmar:

\begin{abstract}
En conclusión fábula y realidad no tienen por qué contraponerse y Lutero lo tuvo en cuenta para que su traducción de la Biblia fuera didácticamente efectiva. Así, en la traducción luterana de la Septuagésima, la palabra griega 'mythos' se tradujo por el término 'fabula', cuando se trata de la narración moralizante de dicho texto bíblico (Dithmar, 1988: 164). En relación a lo anterior, Reinhard Dithmar menciona el resultado al que llegó Adolf Jülicher en su monumental obra Die Gleichnisreden Jesu, cuando dice que "de hecho, pertenece a la esencia de la fábula, el que actualice un suceso pasado y acabado, el que comunique la realidad del mito"7 (Jülicher, 1976: 98).
\end{abstract}

\title{
5. LA INFLUENCIA DE ESOPO EN EL USO DE LA FÁBULA POR LUTERO.
}

Esopo gozaba de una gran influencia en la sociedad de la época, gracias a la cobertura que le daban las fábulas. Para Lutero, Esopo era mucho más que el creador de las fábulas. Representaba, por una parte, el modelo de crítica a la sociedad de la época y, por otra, era el autor de fábulas con las que educar a niños en la verdad y el amor al arte. Fue lo mismo que realizó Heinrich Heine con su Wintermärchen para criticar la sociedad alemana sin ser censurado.

Precisamente, debido a la admiración que Lutero sentía por Esopo, se fijó el objetivo de depurar la traducción de las Fábulas de Esopo que hizo Steinhöwel, lo que le llevaría a publicar un libro que contuviera aquellas fábulas más esenciales y útiles, y que estuvieran al nivel de la fe religiosa, aunque hicieran reír. Por esto se ha dicho que Lutero "quiere completar su propio Esopo, el Esopo puro, que recomienda a todos los corazones piadosos en lugar del Esopo alemán y pecaminoso, con una Vita Esopi" 8 (Dithmar, 1988: 39). El libro apareció por primera vez en 1557, en el quinto volumen de su edición de Jena, con el título Las fábulas completas de Esopo, vertidas al Alemán por DML, con una cuidada introducción para el uso y satisfacción de dicho libro por toda persona de cada estamento, para que lo lean con deleite y aprovechamiento.

No cabe duda, pues, de la importancia del significado político de la figura de Esopo ni de su utilización con fines religiosos. Sin embargo, Lutero concibió estos objetivos con ambición tal que deseó que ese libro fuera leído por todos los miembros de la sociedad.

\section{INFLUENCIA DE LA FÁBULA EN LA LABOR TRADUCTORA DE LUTERO}

El interés que la fábula despertó en Lutero se vio reflejado en su labor de traducción. Su búsqueda por la sencillez del lenguaje y que fuera accesible al pueblo

\footnotetext{
${ }^{7}$ La traducción de la cita la ha sido realizada por el autor del artículo, cuyo texto en el original alemán es el siguiente: "gehört es zum Wesen der Fabel, da $\beta$ sie Vergangenes, Vollendetes beibringt, da $\beta$ sie ihrem Mythus kuhn der Wirklichkeit zuteilt".

${ }^{8}$ La traducción de la cita la ha sido realizada por el autor del artículo, cuyo texto en el original alemán es el siguiente: "Denn er (Lutero) will seinen eigenen, den gereinigten Esopus, den er allen ‘frommen Herzen' an Stelle des 'Deudschen shändlichen Esopum' Steinhöwels empfielt, durch eine Vita Esopi ergänzen".
} 
le llevó a utilizar al máximo en la traducción aquellos géneros literarios que facilitaran dicho objetivo, entre los que está la fábula. La traducción de la Biblia a la lengua alemana será la ocasión.

Los dos criterios o principios que orientan la obra de traducción de Lutero son: no alejarse de la letra y al mismo tiempo prescindir de la materialidad de la letra (García Yebra, 1979: 25-26). Siguiendo estos dos criterios, Lutero es consciente de que las enseñanzas que abundan en la Biblia, al igual que en la fábula, no radican solo en lo que se dice ni en lo que está en el texto. Por ello Lutero señala que las traducciones no deben oscurecer el significado metafórico de las alegorías y parábolas, especialmente las de la Biblia; por eso "defiende sin ambajes, en los Sumarios sobre los salmos y causas de la traducción, que «no es el sentido que debe servir a las palabras sino las palabras al sentido»" (Brandenberger, 2002: 25).

Esta forma de entender Lutero la traducción le lleva a utilizar en su traducción bíblica un alemán cercano al hombre sencillo, que apelara a sus conocimientos previos y a su experiencia cotidiana y donde lo fabuloso, interesante y emocionante hiciera creíble el mito. En el siguiente fragmento de su obra El arte de traducir, Lutero deja traslucir perfectamente su forma de entender y de realizar el uso de la lengua, en este caso de la lengua alemana, para que todos le entiendan:

No hay que solicitar a estas letras latinas, cómo hay que hablar el alemán, que es lo que hacen esos borricos; a quienes hay que interrogar es a la madre en la casa, a los niños en la calle, al hombre corriente en el mercado, y deducir su forma de hablar fijándose en su boca. Después de haber hecho esto es cuando se puede traducir: será la única manera de que comprendan y de que se den cuenta de que se está hablando con ellos en alemán (Lutero, 2006: 311).

\section{LA FÁBULA Y SU USO DIDÁCTICO}

Lutero contribuyó a mostrar la utilidad didáctica de un género como la fábula que persigue como objetivo favorecer el conocimiento de la lengua y el sentido crítico, expresado mediante la moraleja de la fábula. Por ello, Lutero consideró las fábulas como un material didáctico útil para el aula, al facilitar el aprendizaje de la lengua, favorecer el desarrollo del sentido crítico en los alumnos y mostrar el valor moralizante de las conductas, como aparece en su obra Tischreden (Charlas de sobremesa) al relatar historias cortas de esta naturaleza, como anteriormente hizo Erasmo de Roterdam en sus Adagia.

Coherentemente con el valor que Lutero y Melanchton le atribuyen a la fábula por ser un buen instrumento didáctico para la educación de los alumnos, tienen muy en cuenta dicha estima, e incluyen la enseñanza de las fábulas de Esopo en el curriculum escolar de la escuela alemana reformada. No cabe duda que la cohabitación en la fábula de elementos reales y de ficción puede fomentar la creatividad en la escuela y favorece también la preparación para la vida real. Posiblemente éstos y el resto de aspectos señalados en el artículo, expliquen la pervivencia de este género a lo largo del tiempo (Rodríguez Adrados, 1979: 11). 


\section{CONCLUSIÓN}

El recurso a la fábula como género literario y su uso didáctico desde la perspectiva cultural de los renacentistas y reformistas alemanes, entre los que sobresalen Lutero y Melanchton, ha contribuido a comprender su valor educativo y a ser transmisora de la verdad de la vida. La necesidad de relacionar el mundo real y el mundo de la educación en el que se utilizan elementos simbólicos y ficticios para el aprendizaje, es intrínseco a la visión de la fábula, en general, y también a la visión luterana de la fábula.

\section{BIBLIOGRAFÍA}

Barbolani, C. (2006): “Introducción”, en J. de Valdés: Diálogo de la lengua, Madrid, Ediciones Cátedra.

Brandenberger, T. (2002): “Introducción”, en M. Lutero: Carta sobre el arte de traducir, Madrid, Caparrós Editores.

Cáceres, I. y Martín-Gaitero, R. (1994): “Los refranes flamencos de Pieter Bruegel", Revista Paremia, $\mathrm{n}^{\mathrm{o}} 3$.

Certeau, M. (2006): La fábula mística (siglos XVI-XVII), Madrid, Ediciones Siruela.

Dicke, G. (1994): Heinrich Steinhöwels Esopus und seiner Fortsetzer: Untersuchungen zu einem Bucherfolg der Frühdruckzeit, Tübingen, Niemeyer.

Dicke, G. y Grubmüller, K. (1987): Die Fabeln des Mittelalters und der FrèHeren Neuzeit. Ein Katalog der deutschen Versionen und ihrer lateinischen Entsprechungen, München, Fink.

Dithmar, R. (1988): Die Fabel, Padeborn, Ferdinand Schöningh.

Egido, T. (ed.) (2006): Lutero. Obras, Salamanca, Ediciones Sígueme.

Franck, S. (1541): Sprichwörter, Schöne, Weise, Herrliche, Clugreden, und Hoffspruch (reproducción de la ed. Frankfurt 1541, con un prefacio de Wolfgang Mieder), Hildescheim, Olms.

García Yebra, V. (1979): “Lutero, traductor y teórico de la traducción”, Revista Arbor, Tomo CII, no 399-Marzo: 23-34.

Gilly, C. (2005) : "Erasmo, la Reforma radical y los heterodoxos radicales españoles", en T. Martínez Romero (Editor): Les lletres hispaniques als segles XVI, XVII i XVIII, Castelló de la Plana, Publications de la Universitat Jaume I.

Grane, L. (1975): Modus Loquendi Theologicus. Luthers Kampf um die Erneuerung der Theologie (1515-1518), Leiden, E.J. Brill.

Grubmüller, K. (1977): Meister Aesopus. Untersuchungen zu Geschichte und Function im Mittelalter, Zürich-München, Artemis.

Janssen, J. (1925): “La cultura alemana antes y después de Lutero”, en Historia Universal, Vol. VIII bis, Barcelona, Librería Religiosa. 
Jülicher, A. (1976): Die Gleichnisreden Jesu. Zwei Teile in einen Band, Darmstadt (Impresión reprografiada de la edición de dos volúmenes, $2^{\text {a }}$ Edición, 1910).

Koyré, A. (1981): Místicos, Espirituales y Alquimistas del siglo XVI alemán, Madrid, Akal.

Lapesa, R. (1974): “Introducción” (Selección, estudio y notas), en J. de Valdés: Diálogo de la lengua, Zaragoza, Editorial Ebro.

Lilje, H. (1986): Lutero, Barcelona, Salvat Editores.

Lutero, M. (2006): Obras. Edición preparada por T. Egido, Salamanca, Ediciones Sígueme.

Monreal, J. L. (2011): “Juan de Valdés, humanista y lingüista”, Revista Cuadernos del Institu to Historia de la Lengua, 6: 141-173.

Monreal, J. L. (2012): “La perspectiva religiosa y el uso de la lengua en Lutero”, Revista Futhark, 7: 189-227.

Mourelle de Lema, M. (1993): “Fundamentos filosóficos del Humanismo de Vives”, en Juan Luis Vives, Madrid, Grugalma.

Ortega, A. (2002): Fray Luis de León, humanista, Salamanca, Editorial CEIAS.

Paris, C. (1962): “Vives y la formación del saber moderno", en Anales de la Cátedra Francisco Suarez, 2, Fasc. 2. Universidad de Granada: 235-264.

Rodríguez Adrados, F. (1979): Historia de la fábula greco-latina, Madrid, Editorial de la Universidad Complutense.

Serrano, A. (1992): “La fábula grecolatina en los Adagia de Erasmo y su influencia en el humanista Fernando de Arce", Revista Myrtia, 7: 49-80.

Suárez, R. T. (2003): “El sentido histórico del proyecto educativo de Lutero" (I), Revista Frónesis, Vol. 10, 3: 1-31.

http:/ / www.revistas.luz.edu.ve/index.php/frone/article/view/63

(Consultado en noviembre de 2012).

Talavera, S. (2007): La fábula esópica en España en el siglo XVIII, Cuenca, Ediciones de la Universidad Castilla-La Mancha.

Valdés, J. (1997): “Diálogo de la lengua”, en Obras Completas, I. Diálogos, Escritos espirituales. Cartas, Madrid, Ediciones de la Fundación José Antonio de Castro. 